\title{
OSCILAÇÕES DA TEMPERATURA DO SOLO EM FUNÇÃO DE QUANTIDADES DE PALHA E HORÁRIOS AO LONGO DO DIA
}

\author{
SOIL TEMPERATURE FLUCTUATIONS IN THE AMOUNTS OF STRAW FUNCTION
}

AND TIMES THROUGHOUT THE DAY

\begin{abstract}
Gilberto Aparecido Rodrigues - gilberto.rodrigues@ fatectq.edu.br Faculdade de Tecnologia de Taquaritinga (FATEC) - SP - Brasil

Gilmar Oliveira Santos - gilmar@unirv.edu.br

Universidade de Rio Verde (UNIRV) - GO - Brasil

Arthur Carrasqueira - arthur.carrasqueira@fatectq.edu.br

Faculdade de Tecnologia de Taquaritinga (FATEC) - SP - Brasil

Elizete Rodrigues Machado - elizeterodrigues91@ @otmail.com

Faculdade de Tecnologia de Jaboticabal (FATEC) - SP - Brasil

Elaine Therezinha Assirati - elaine.assirati@fatectq.edu.br

Faculdade de Tecnologia de Taquaritinga (FATEC) - SP - Brasil

Rita de Cássia Vieira Macri - pro.ritacvm@fatecjaboticabal.edu.br

Faculdade de Tecnologia de Jaboticabal (FATEC) - SP - Brasil
\end{abstract}

DOI: $10.31510 /$ infa.v15i1.353

\section{RESUMO}

A cobertura vegetal morta sobre o solo reduz a luminosidade, a temperatura e mantém a umidade do solo. A redução da temperatura do solo pode trazer benefícios para o ecossistema solo-planta. O objetivo deste artigo foi de avaliar as oscilações da temperatura do solo em função de quantidades aplicadas de palha e horários de avaliação. O experimento foi realizado na Unesp-Jaboticabal, SP, no setor de irrigação, montado em um delineamento em blocos casualizados (DBC), compreendendo 4 quantidades de palha, 4 horários de avaliação e 4 repetições. Foram analisados os efeitos da quantidade de palha (zero, 5, 10 e $15 \mathrm{Mg} \mathrm{ha}^{-1}$ ) e horários de avaliação (HA1: 9 h, HA2: 11h; HA3:14h e HA4: 16h). Foi avaliada a temperatura do solo na profundidade de $10 \mathrm{~cm}$ do solo, com o uso um termômetro de solo. A palha utilizada foi produzida no próprio local experimental, fenada e reservada para distribuição nos respectivos tratamentos. Os resultados indicaram que a adição de palha ao solo de 5, 10 e $15 \mathrm{Mg} \mathrm{ha}^{-1}$ foram suficientes para garantir redução da temperatura do solo em pelo menos $3^{\circ} \mathrm{C}$. A presença de palha sobre o solo exerceu papel físico de isolante para o aquecimento do solo, e de manutenção da umidade do solo.

Palavras-chave: Aquecimento do solo. Cobertura morta. Brachiaria 


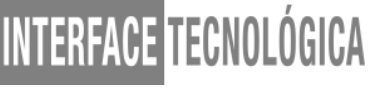

\begin{abstract}
The dead vegetation on the ground reduces the brightness, temperature and maintains soil moisture. The reduction in soil temperature can bring benefits to the soil-plant ecosystem. The aim of this paper was to evaluate the soil temperature fluctuations due to amounts used straw and evaluation schedules. The experiment was carried out at Unesp-Jaboticabal, SP, in the irrigation sector, set up in a randomized block design (RBD), comprising 4 volumes of straw, 4 hours of evaluation and 4 repetitions. We analyzed the effects of the amount of straw (zero, 5, 10 and $15 \mathrm{Mg} \mathrm{ha}^{-1}$ ) and time evaluation (HA1: $9 \mathrm{~h}, \mathrm{HA} 2: 11 \mathrm{~h}$; HA3: 14h and HA4: 16h). The soil temperature was measured at a depth of $10 \mathrm{~cm}$ of soil, using a soil thermometer. The straw used was produced in own experimental site into hay and reserved for distribution in their treatments. The results indicated that adding straw to soil in 5, 10 and $15 \mathrm{Mg} \mathrm{ha}^{-1}$ was sufficient to ensure reduction of soil temperature at least $3{ }^{\circ} \mathrm{C}$. The presence of straw on the ground plays insulation physical role for the heating of the soil, and soil moisture maintenance.
\end{abstract}

Keywords: Heating the soil. Mulch. Brachiaria

\section{INTRODUÇÃO}

A quantidade de cobertura vegetal morta sobre o solo modifica a luminosidade (GOMES et al., 2014), principalmente diminuindo a incidência de radiação solar, a amplitude da temperatura na camada superficial do solo pelo uso de cobertura sobre o solo, mantendo elevados teores de umidade do solo. Além disso, é possível que a palha, ou outra cobertura do solo, exerça um papel alelopático sobre ervas daninhas (TREZZI et al.2006), alterando a possibilidade de brotação de sementes destas plantas (CLEMENTS et al., 1996; GOMES Jr. e CHRISTOFFOLETI, 2008). A escolha da espécie para formação de palha é muito importante no plantio direto, influindo diretamente na implantação e manutenção do sistema de plantio. É indispensável, antes da implantação da cultura, uma boa formação de cobertura vegetal na superfície do solo, na implantação do plantio direto (ALMEIDA, 1991; ALVARENGA et al., 2001). Porém, a escolha adequada das plantas que fornecem a palhada pode se tornar um problema, por existirem diferenças edafoclimáticas entre as regiões, podendo assim não obter o êxito com esse sistema (ANDRIOLI, 2004).

O Brasil, por sua vasta extensão territorial, possui diferentes tipos de clima, e em algumas épocas do ano possuem um clima seco no período do inverno, com a diminuição do fotoperíodo, dificultando a implantação de plantas nesta época do ano. Assim, no sul do Brasil o uso de palhada sobre o solo, ou uso de coberturas de plantas anuais ou perenes, dessecadas ganhou projeção através do plantio direto (ALTIERI et al., 2011), protegendo o 


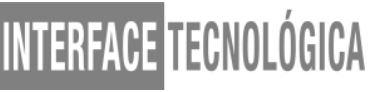

solo e até ajudando no controle de ervas daninhas. A integração do uso de palha de gramíneas ou leguminosas, com a utilização de dose baixa de herbicidas, pode resultar em sistemas de cultivo eficazes no controle de plantas daninhas e mais adequadas quanto ao aspecto ambiental, tanto pela redução do uso de herbicidas quanto pelo aproveitando dos benefícios do sistema de plantio direto (MARCHESAN et al. 2016).

\section{FUNDAMENTAÇÃO TEÓRICA}

É comum na região do Cerrado do Brasil, encontrar uma grande dificuldade de estabelecer plantas semeadas com a finalidade de fornecer palhada para a cobertura do solo (ALVARENGA et al., 2001). Entretanto, na região Sul do País, região esta que é bem difundida a técnica do plantio direto, utiliza-se com frequência a cultura da aveia, a qual é utilizada como cobertura de solo. Já na região Central ou Centro-Oeste do Brasil, o milheto cumpre esse papel (SALTON, 2001). A utilização de espécies forrageiras, tal como as espécies do gênero Brachiaria ruziziensis (Sinônimo: Echinochloa ruziziensis) para a formação de palhada, vem sendo mais utilizada e pesquisada por agricultores e pesquisadores recentemente (APDC, 2001; BERNARDES, 2003; TORRES, 2003; ANDRIOLI, 2004).

A Brachiaria tem um grande papel na manutenção e persistência da palhada sobre o solo, devido a sua relação $\mathrm{C} / \mathrm{N}$ relativamente alta, ocorrendo atraso na decomposição deste material, garantindo assim a cobertura do solo por mais tempo, principalmente nas regiões mais quentes. Nas regiões mais quentes e chuvosas, de clima tropical, as pesquisas mostram que ocorre uma limitação na manutenção de palhada sobre o solo ao longo do tempo, devido a rapidez de decomposição da matéria vegetal (PEREIRA, 1990; LANDERS, 1995), expondo o solo a aumentos de temperatura e riscos com arraste das frações do solo e seus nutrientes.

Por sua considerável produção de biomassa durante todo o ano, as Brachiarias se destacam, oferecendo uma grande quantidade de cobertura vegetal do solo, e segundo Bernardes (2003), o gênero Brachiaria, por sua capacidade de rápida cobertura do solo, tem sido adotada como forrageira para a produção de massa, com o objetivo de cobertura do solo, em sistema de plantio direto. A cobertura morta sobre o solo aliada à irrigação, foram investigados por Resende et al. (2015), que constataram que a cobertura morta resultou em uma retenção média de água aplicada, na irrigação por microaspersão, de aproximadamente $60 \%$, para os dois tipos de palha utilizados, com relação C/N altas. 
A utilização da cobertura morta no solo, no cultivo de hortaliças, foi abordada por Resende et al. (2005), que constataram que o uso de cobertura morta sobre o solo foi considerado uma prática vantajosa para o cultivo de hortaliças de verão, a qual teve um efeito na redução da temperatura do solo em até $3,5^{\circ} \mathrm{C}$. Além disso, houve aumento a retenção de umidade do solo em até $2,3 \%$ em relação à testemunha, e melhorou visualmente o desenvolvimento das hortaliças. O objetivo deste artigo foi de avaliar as oscilações da temperatura do solo em função de quantidades aplicadas de palha e horários de avaliação.

\section{PROCEDIMENTOS METODOLÓGICOS}

O experimento foi conduzido na Fazenda Experimental da FCAV-UNESP, Jaboticabal, SP, na latitude de $21^{\circ} \mathrm{S}$, longitude 48o18'58' W e altitude de 595 metros. O solo da área experimental é do tipo Latossolo Vermelho Escuro eutroférrico, textura argilosa, de acordo com o sistema de classificação de solos da Embrapa (2009). O clima no local foi classificado como CWA tropical (KÖPPEN), com verão chuvoso e inverno seco, e uma temperatura média de $22,2{ }^{\circ} \mathrm{C}$. A quantidade média de precipitação anual é de aproximadamente 1.425 milímetros, concentrando-se mais entre outubro e março. O delineamento utilizado foi do de blocos casualizados, em esquema fatorial 4 x 4 , com 4 repetições, no qual o primeiro fator correspondeu a quantidades de palha(QP) de Brachiaria brizantha (P1: 0, P2: 5, P3: 10; e P4: $15 \mathrm{Mg} \mathrm{ha}^{-1}$ ), o segundo fator foi horários de avaliação(HA), sendo HA1: 9h; HA2: 11h; HA3:14 h e HA4: 16h, sendo a proposta adaptada dos escritos de Ribas et al.(2015).

A área experimental foi inicialmente cultivada com Brachiaria (Syn. Urochloa) brizantha cv. Marandu, de novembro de 2012 a julho de 2013, quando a forrageira foi dessecada com glifosato, seguido da sua remoção com enxada. Em seguida, o terreno foi preparado com enxada rotativa, em duas passadas, na profundidade de $15 \mathrm{~cm}$, e, em seguida a área foi utilizada em experimento de avaliação de emissões de $\mathrm{CO}_{2}$, em função de manejos de palha e lodo de esgoto. Esta área, após o uso experimental, ficou mantida limpa e sem crescimento de nenhum tipo de vegetal até o início deste experimento, em janeiro de 2015.

A palha foi colhida e fenada no próprio local, resultado de cortes mensais de condução de outros experimentos no local, foi fenada ao sol e sua matéria seca determinada $(15 \%)$ e as quantidades preestabelecidas, depositadas em diferentes quantidades sobre cada parcelas de dimensões de $1 \mathrm{~m}$ x $1 \mathrm{~m}$, correspondendo a zero, 5, 10 e $15 \mathrm{Mg} \mathrm{ha}^{-1}$ de palha de 
Brachiaria. A temperatura do solo foi medida a $10 \mathrm{~cm}$ de profundidade em cada parcela, com o auxílio de um termômetro de solo da marca Minipa, com visor digital, e aguardando o tempo de estabilização da temperatura de dez segundos para uma nova tomada de temperatura. Os horários de avaliação da temperatura do solo foram as 9h, 11h, 14h e 16h, durante 7 dias de avaliação consecutivos. Desta forma, o objetivo deste artigo foi avaliar as oscilações da temperatura do solo, em função de quantidade de palha em quatro diferentes horas do dia, em um Latossolo Vermelho eutroférrico. Para avaliar os efeitos dos tratamentos, quantidades de palha (4) e horários de avaliação (4), procedeu-se inicialmente a análise de variância pelo teste $\mathrm{F}$ a $5 \%$ de probabilidade, seguido pelo teste de comparação de médias, pelo teste de Scott Knott, a nível de 5\% de probabilidade.

\section{RESULTADOS E DISCUSSÃO}

Os resultados do teste $\mathrm{F}$ indicaram que houve diferença significativa a $5 \%(\mathrm{P}<0,05)$ para diferentes quantidades de palha(QP) aplicadas ao solo, além disso, houve diferença significativa nos horários de avaliação (HA) e interação entre QP e HA (Tabela 1). Estes resultados são coerentes, pois maiores quantidades de palha sobre o solo protegem mais da ação dos raios solares, amenizando o efeito na elevação da temperatura do solo. Nos primeiros horários da manhã, a radiação solar é muito menor comparada aos horários à tarde, refletindo em temperaturas mais amenas nos horários da manhã (ACOSTA et al. 2004).

Tabela 1. Análise de variância da aplicação de diferentes quantidades de palha (QP) sobre o solo e horários de avaliação (HA), na temperatura do solo, em um Latossolo Vermelho Escuro eutroférrico

\begin{tabular}{lccc}
\hline Fonte de variação (FV) & Graus de liberdade (GL) & QM & Fc \\
\hline Palha (QP) & 3 & 647,43 & $375,92^{*}$ \\
\hline Horários de Avaliação (HA) & 3 & 1194,75 & $693,71^{*}$ \\
\hline Palha*Horário (QP*HA) & 9 & 219,25 & $127,31^{*}$ \\
\hline Bloco & 3 & 99,89 & $58,00^{*}$ \\
\hline Resíduo & 749 & 1,72 \\
\hline Total & 767 & \\
*Indica que o teste foi significativo a 5\% de probabilidade pelo teste de Scott Knott. \\
Fonte: Os autores (2015)
\end{tabular}

Os resultados deste estudo concordam com Acosta et al. (2004), em que maiores acréscimos de resíduos ao solo proporcionaram condições mais satisfatórias para a manutenção da umidade do solo, e melhor infiltração da água após precipitação natural. Além disso, contribuiu para que a temperatura do solo diminuísse, em média, cerca de $0,6^{\circ} \mathrm{C}$ 


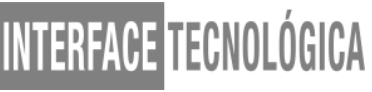

a cada tonelada de resíduo adicionado ao solo. Relatam ainda, com o fato de solos descobertos, na época de verão, terem a temperatura aumentada significativamente em relação aos solos que tem a adição de palha ou outra cobertura sobre o solo. Resende et al. (2015) constataram que a cobertura morta proporcionou uma maior retenção de água no solo, em plantas de coqueiros, irrigadas por microaspersão, para as coberturas mortas utilizadas. Semelhantes resultados foram encontrados por Resende et al. (2005), ao utilizarem a cobertura morta sobre o solo, para o cultivo de cenoura no verão, de tal sorte que a temperatura reduziu em até $3,5^{\circ} \mathrm{C}$, em áreas com cobertura morta, aumentou a retenção de umidade do solo em até $2,3 \%$ em relação ao solo descoberto, e ainda contribuiu para um melhor desenvolvimento da cultura da cenoura.

O teste de médias mostrou que houve efeito significativo $(\mathrm{P}<0,05)$ das quantidades de palha (QP) e horários de avaliação (HA), ou seja, menores quantidades de palha, nos horários das 11 às 16 horas apresentaram as mais elevadas temperaturas em relação ao horário das 9 horas, quando a radiação solar global incidente no verão é superior a outras épocas do ano (HELDWEIN et al.,2012) sobre a área, provavelmente promoveu pouco aquecimento do solo. A maior amplitude na variação da temperatura em função das quantidades de palha, ocorreu no horário das 16h, seguido pelos horários das 14 e 13 horas (Tabela 2). Os valores de temperatura do solo nú (dose 0 de palha), apresentou diferença significativa em relação as quantidades de palha utilizados de 5, 10 e $15 \mathrm{Mg} \mathrm{ha}^{-1}$. Doses de palha variando de 5 a $15 \mathrm{Mg}$ $\mathrm{ha}^{-1}$, não apresentaram diferenças significativas entre si na redução da temperatura do solo, no entanto, maiores quantidades de palha, além de proporcionar menores temperaturas do solo, permitiram provavelmente a criação de ambiente mais propicio para isolamento(ARAUJO et al.,1999; HECKLER et al., 2007; DALMAGRO et al., 2014), ao longo do tempo, provavelmente resultado da maior cobertura do solo(PEZZOPANE et al.,1996), e possivelmente pode trazer outros benefícios, entre eles, evitar a erosão do solo, fornecer maior quantidade de nutrientes para o solo, via degradação do material de cobertura, e manutenção da umidade do solo (BRAGAGNOLO e MIELNICZUK,1990).

$\mathrm{Na}$ condição de aplicação de elevadas quantidades de palha sobre o solo, em ambiente cultivado por culturas anuais ou perenes, é possível incrementar a taxa de crescimento das plantas, manutenção de temperatura do solo mais adequada para as raízes, melhorar aeração do solo e colaborar na taxa de degradação do material de cobertura (OLIVEIRA et al., 1999; OLIVEIRA et al., 2001). Neste aspecto, o favorecimento no crescimento de raízes é muito positivo, e supondo haver restrição nas quantidades de palha sobre o solo, em sistemas de 


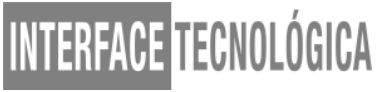

produção com plantas anuais, fica evidente que $5 \mathrm{Mgha}^{-1}$ de palha sobre o solo, oferece benefícios significativos. Em ambientes onde há sistema de irrigação implantado, é possível que as doses de até $15 \mathrm{Mgha}^{-1}$ proporcionem maior persistência da cobertura morta sobre o solo ao longo do ciclo da cultura, principalmente evitando condições para início de erosão laminar.

No preparo convencional do solo, as elevadas temperaturas do solo, pela exposição do solo por longos períodos (ARAUJO et al.,1999; DAMAGRO et al., 2014), podem provocar efeitos negativos sobre sementes, plântulas e raízes, e na atividade microbiana do solo, provocando também a perda de água por evaporação, pois a secagem da superfície do solo acontece com maior rapidez (DERPSCH et al., 1991). Neste estudo, verificou-se que a temperatura média do solo, onde não houve presença de palha, mostrou as mais elevadas temperaturas médias $\left(32,68{ }^{\circ} \mathrm{C}\right)$. Nos tratamentos com 5, 10 e $15 \mathrm{Mg} \mathrm{ha}^{-1}$, embora as médias das temperaturas do solo apresentassem valores muitos próximos, estas diferenças não foram significativas, mas a interação significativa entre temperatura do solo e doses de palha, ressalta a importância da cobertura do solo na redução da temperatura do solo (BELAN et al., 2013).

Tabela 2. Teste de médias dos efeitos da quantidade de palha e horários de avaliação, na temperatura do solo.

\begin{tabular}{lccccc}
\hline Horários & \multicolumn{5}{c}{ Quantidades de Palha } \\
\cline { 2 - 6 } & $0 \mathrm{Mg} \mathrm{ha}^{-1}$ & $5 \mathrm{Mg} \mathrm{ha}^{-1}$ & $10 \mathrm{Mg} \mathrm{ha}^{-1}$ & $15 \mathrm{Mg} \mathrm{ha}^{-1}$ & Médias \\
\hline 9 & $26,27 \mathrm{bD}^{*}$ & $27,27 \mathrm{aD}$ & $27,33 \mathrm{aD}$ & $27,83 \mathrm{aC}$ & 27,17 \\
11 & $29,82 \mathrm{aC}$ & $28,22 \mathrm{bC}$ & $28,16 \mathrm{bC}$ & $28,29 \mathrm{bC}$ & 28,62 \\
14 & $36,04 \mathrm{aB}$ & $30,39 \mathrm{bB}$ & $29,63 \mathrm{cB}$ & $29,27 \mathrm{cB}$ & 31,33 \\
16 & $38,57 \mathrm{aA}$ & $31,63 \mathrm{bA}$ & $30,42 \mathrm{cA}$ & $29,97 \mathrm{cA}$ & 32,65 \\
\hline Médias & 32,68 & 29,38 & 28,88 & 28,84 & \\
\hline
\end{tabular}

* Letras minúsculas iguais na mesma linha e letras maiúsculas iguais na mesma coluna, não diferem estatisticamente ao nível de 5\%(P<0,05), pelo teste de Scott Knott.

Fonte: Os autores (2015).

A associação entre temperatura do solo e quantidades de palha demonstra que à medida que se aumenta a quantidade de palha, há um efeito na redução da temperatura do

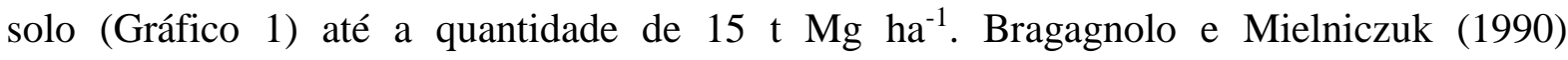
mostraram que a cobertura morta sobre o solo ameniza as perdas de água por evaporação, e também diminui as temperaturas do solo. Unger (1978) verificou que a cobertura de palha de milho sobre o solo, propiciou uma queda na temperatura do solo a $10 \mathrm{~cm}$ de profundidade, e essa redução de temperatura se intensificava diretamente com o aumento da quantidade de 
palha adicionada ao solo. Segundo Pezzopane et al. (1996), os resíduos vegetais possuem uma baixa condutividade térmica, e uma alta refletividade à radiação solar. Assim, atuam na redução de oscilação térmica do solo, reduzindo também a perda de água por evaporação. Contudo, quanto mais água é encontrada no solo, sua temperatura é amenizada por mecanismo físico de troca de calor, inclusive nos horários de maior incidência de radiação solar.

Grafico 1. Variações da temperatura do solo em função de doses de palha sobre o solo

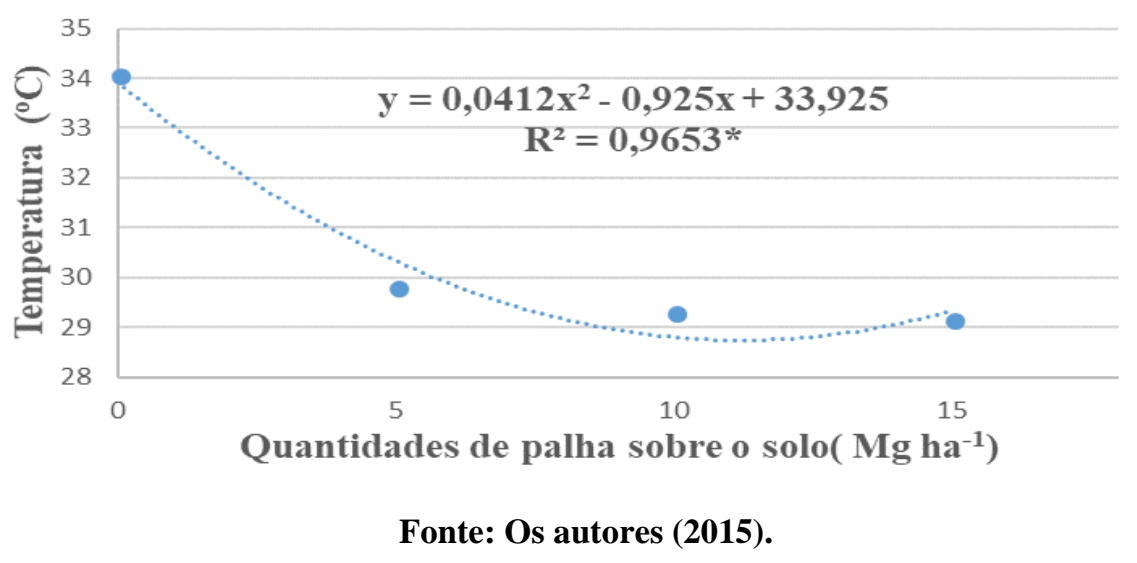

Gráfico 2 . Variações entre temperatura do solo em função dos horários de avaliação

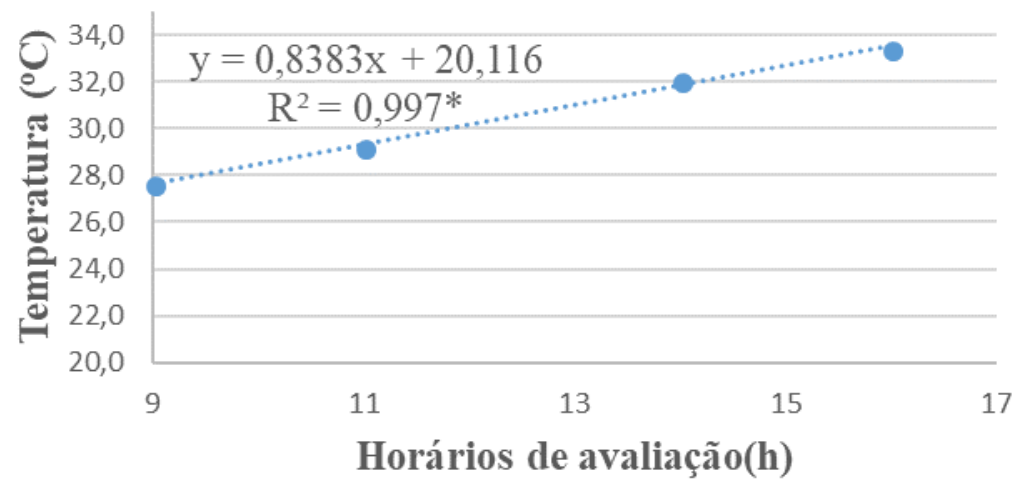

Fonte: Os autores (2015).

Oscilações da temperatura no perfil do solo foram abordadas por Belan et al. (2013), e constataram que a temperatura no perfil do solo variou em função da profundidade e do aporte de cobertura morta. O solo sob condição de ausência de palha em cobertura, a 


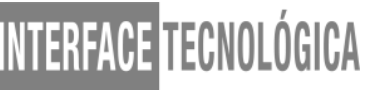

temperatura do solo apresentou maiores amplitudes ao longo do dia, e essas amplitudes provavelmente podem ter variado ao longo do perfil do solo. As maiores amplitudes térmicas e os horários de avaliação em que ocorrem os valores máximos de temperatura foram diferentes, e ocorreram próximo das 16h, semelhantes aos resultados deste estudo. Verificaram ainda que houvesse correlação positiva entre a temperatura do ar e a temperatura do solo, no que diz respeito à presença e ausência de cobertura vegetal morta, indicando o papel de isolante do material morto sobre o solo, e essa relação são reduzidas gradativamente ao longo do perfil do solo.

Os horários de avaliação da temperatura do solo (Gráfico 2) mostram claramente que a elevação da temperatura do solo a partir das $9 \mathrm{~h}$ até as 16 horas. Nos períodos mais quentes é provável que o efeito sobre a fisiologia das plantas possa ser um tanto negativo, em função de maiores perdas por transpiração, mas que no campo pode ser amenizado pela manutenção de palha sobre o solo na quantidade que varia de 10 a $15 \mathrm{Mgha}^{-1}$.

\section{CONCLUSÃO}

A quantidade adição de palha ao solo de 5, 10 e $15 \mathrm{Mg} \mathrm{ha}^{-1}$ foram suficientes para garantir redução da temperatura do solo em pelo menos $3^{\circ} \mathrm{C}$. Os horários da manhã apresentaram as menores amplitudes de temperatura do solo, diferentemente das temperaturas próximo às 16 horas. A presença de palha sobre o solo exerce papel físico de isolante para o aquecimento do solo, e de manutenção da umidade do solo.

\section{REFERÊNCIAS}

ACOSTA, J. A. de A.; GIRARDELlO, V.; WEBER, MIRLA A.; ROSSATO, O. B.; SANTI, O. G. R.; LOVATO, T. ; AMADO, T. J. C. Efeito na temperatura e na umidade do solo pelo aporte de resíduos orgânicos de culturas de cobertura. In: VII Encontro Latino Americano de Iniciação Científica e IV Encontro Americano de Pós-Graduação. Anais... Universidade do Vale do Paraíba, p.15151-1518, 2004. Disponível em: < http://www.inicepg.univap.br/cd/INIC_2004/trabalhos/epg/pdf/EPG5-9.pdf>. Acesso em: Acesso:22 Jul. 2015.

ALMEIDA, F.S. Controle de plantas daninhas em plantio direto. Londrina: Instituto Agronômico do Paraná, 1991. 34p. (Circular, 67). 
ALTIERI, M. A.; LANA, M.A.; BITTENCOURT, H.V.H.; KIELING, A.S.; COMIN, J.J. ; LOVATO, P.E. Enhancing crop productivity via weed suppression in organic no-till cropping systems in Santa Catarina, Brazil. Journal of Sustainable Agriculture, v.35, n.8, p.855-869, 2011. Disponível em:<http://dx.doi.org/10.1080/104 40046.2011.588998>. Acesso:22 Jul. 2015.

ALVARENGA, R.C.; CABEZAS, W.A.L.; CRUZ, J.C. \& SANTANA, D.P. Plantas de cobertura de solo para sistema de plantio direto. Informe Agropecuário, Belo Horizonte, v. 22, n. 208, p. 25-36, 2001.

ANDRIOLI, I. Plantas de cobertura em pré-safra à cultura do milho em plantio direto, na região de Jaboticabal-SP. 2004. 78f. Tese (Livre-Docente) - Faculdade de Ciências Agrárias e Veterinárias, Universidade Estadual Paulista, Jaboticabal. 2004.

APDC- Associação de Plantio Direto no Cerrado. Braquiária mais que pasto II. Brasília, 2001. p.4. (Boletim Informativo, 6).

BELAN, L. L.; XAVIER, T. M. T.; TORRES, H.; TOLEDO, J. V. ; PEZZOPANE, J. E. M. Dinâmica entre temperaturas do ar e do solo sob duas condições de cobertura. Rev. Acad., Ciênc. Agrár. Ambient. Curitiba, v. 11, Supl. 1, p. S147-S154, 2013.

BERNARDES, L.F. Semeadura de capim-braquiária em pós emergência da cultura do milho para obtenção de cobertura morta em sistema de plantio direto. 2003. 42f. Dissertação (Mestrado) - Faculdade de Ciências Agrárias e Veterinárias - UNESP, 2003.

BRAGAGNOLO, N. \& MIELNICZUK, J. Cobertura do solo por palha de trigo e seu relacionamento com a temperatura e umidade do solo. Revista Brasileira de Ciência do Solo, Campinas, v.14, p.369-374, 1990.

CLEMENTS, D.R., BENOIT, D.L., MURPHY, S.D. ; SWANTON, C.J. 1996. Tillage effects on weed seed return and seed bank composition. Weed Science 44, 314-322.

DALMAGO, G. A.; KOVALESKI S.; HELDWEIN, A. B.; GOUVÊA, J. A. de; CUNHA, G. R. da FOCHESATO, E.; SANTI, A.; PINTO, D. G.; VICARI, M. B. \& SANTOS, M. A. dos. Saldo de radiação em canola em função de diferentes formas de distribuição de palha na superfície In: I Simpósio Latino americano de Canola, 2014, Passo Fundo. Anais...Passo Fundo: Embrapa, 19 a 21 de agosto de 2014,5p.

DERPSCH, R.; ROTH, C.H.; SIDIRAS, N. ; KOPKE, U. Controle da erosão no Paraná, Brasil: Sistemas de cobertura do solo, plantio direto e preparo conservacionista do solo. Eschborn, GTZ, 1991. 272p.

EMBRAPA. Empresa Brasileira de Pesquisa Agropecuária. Centro Nacional de Pesquisa de Solos. Manual de análises químicas de solos, plantas e fertilizantes. 2. ed. Brasília, DF: Embrapa Informação Tecnológica, 2009. 627 p.

GOMES JR., F.G. ; CHIRTOFOLETTI, J.P. Biologia e manejo de plantas daninhas em área de plantio direto. Planta Daninha, v.26, n.4, p.789-798, 2008. Disponível em: <http://dx.doi.org/10.1590/S010083582008000400010>. Acesso:22 Jul. 2015. 


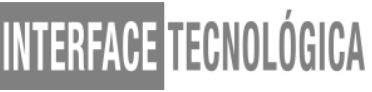

GOMES, D.S.; BEVILAQUIA, N.C.; SILVA, F.B. ; MONQUERO, P.A. Supressão de plantas espontâneas pelo uso de cobertura vegetal de crotalária e sorgo. Revista Brasileira de Agroecologia, v.9, n.2, p. 206-13,2014. Disponível em: <http://www.abaagroecologia.org.br/revistas/index.php/rbagroecologia/ article/view/15333/10200>. Acesso:22 Jul. 2015.

HECKLER, B. M. M.; BERGAMASCHI, H.; COMIRAN, F.; DALMAGO, G. A.; BERGONCI, J.I. MARTORANO, L. G.; KUNZ, J. H. ; DALSIN, F. Trocas de energia na superfície do solo em plantio direto e preparo convencional: I. Balanço de radiação. In: XV Congresso Brasileiro de Agrometeorologia, 2007, Aracaju. Anais... Aracaju: Sociedade Brasileira de Agrometeorologia / Embrapa Tabuleiros Costeiros, 2007. p. 1-5.

HELDWEIN, A. B.; MALDANER, I. C.; BOSCO, L. C.; TRENTIN, G.; GRIMM, E. L.; RADONS, S. Z. ; LUCAS, D. D. P. Saldo de radiação diurno em dosséis de batata como função da radiação solar. Revista Ciência Agronômica, v. 43, n. 1, p. 96-104, jan-mar, 2012.

LANDERS, F. N. Fascículo de experiências de plantio direto no cerrado. Goiânia: APDC, 1995. 261p.

MARCHESAN, E. D.; TREZZI, M. M.; BARANCELLI, M. V. J.; BATISTEL, S. C.; PAGNONCELLI, F. de B. J. ; VIDAL, R. A. Integration mulches with atrazine for weed management in corn. Agrária - Revista Brasileira de Ciências Agrárias, v.11, n.1, p.1-7, 2016.

OLIVEIRA, M.W.; TRIVELIN, P.C.O.; KINGSTON, G.; BARBOSA, M.H.P. ; VITTI, A.C. Decomposition and release of nutrients from sugarcane trash in two agricultural environments in Brazil. In: AUSTRALIAN SOCIETY OF SUGAR CANE TECHONOLOGISTS, 24., Cairns, 2002. Proceedings. Cairns, D.M. Hogarth, 2002. 40p.

OLIVEIRA, M.W.; TRIVELIN, P.C.O.; PENATTI, C.P. ; PICCOLLO, M.C. Decomposição e liberação de nutrientes da palhada de cana-de-açúcar em campo. Pesq. Agropec. Bras., 34:2359-2362, 1999.

PEREIRA, F.A.R. Cultivo de espécies visando a obtenção de cobertura vegetal do solo na entressafra da soja (Glycine max L. Merril) no cerrado. 1990. 83f. Dissertação (Mestrado em Agricultura) - Faculdade de Ciências Agronômicas, Universidade Estadual Paulista, Botucatu, 2002.

PEZZOPANE, J. E. M.; CUNHA, G. de M.; ARNSHOLZ, E. ; COSTALONGA JÚNIOR, M. Temperatura do solo em função da cobertura morta por palha de café. Revista Brasileira de Agrometeorologia, v. 4, n. 2, p. 7-10, 1996.

RESENDE, F. V.; SOUZA, L. de S.; OLIVEIRA, P. S. R de O. ; GUALBERTO, R. Uso de cobertura morta vegetal no controle da umidade e temperatura do solo, na incidência de plantas invasoras e na produção da cenoura em cultivo de verão. Ciência Agrotécnica, v. 29, n. 1, p. 100-105, jan./fev. 2005. 


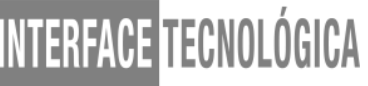

RESENDE, R. S.; SANTOS, H. R.; AMORIM, J. R. A. de; SOUZA, A. G. dos S. ; MENESES, T. N. Efeito da cobertura morta no padrão de distribuição de água em microaspersão. INOVAGRI: Fortaleza, CE, Revista Brasileira de Agricultura Irrigada v.9, n' .5, p. $278-286,2015$.

RIBAS, G. G.; STRECK, N. A.; , SILVA, S. D. DA; , ROCHA, T. S. M. DA; LANGNER, J. A. Temperatura do solo afetada pela irrigação e por diferentes coberturas. Eng. Agríc., Jaboticabal, v.35, n.5, p.817-828, set./out. 2015.

SALTON, J.C. O plantio direto no Brasil. In: SEMINÁRIO INTERNACIONAL SOBRE PLANTIO DIRETO NOS TRÓPICOS SUL-AMERICANOS, 1., 2001, Dourados. Anais... Dourados: Embrapa Agropecuária Oeste, 2001. p.13-15.

TORRES, J.L.R. Estudo de plantas de cobertura na rotação milho-soja em sistema de plantio direto no cerrado, na região de Uberaba-MG. 2003. 108f. Tese (Doutorado em Agronomia) - Faculdade de Ciências Agrárias e Veterinárias, Universidade Estadual Paulista, Jaboticabal-SP.

TREZZI, M.M.; VIDAL, R.A.; MATTEI, D.; SILVA, H.L.; CARNIELETO, C.E.; GUSTMANN, M.S.; VIOLA, R. ; MACHADO, A. Efeitos de resíduos da parte aérea de sorgo, milho e aveia na emergência e no desenvolvimento de plântulas de leiteiro (Euphorbia heterophylla) resistentes a inibidores da ALS. Planta Daninha, Viçosa-MG, v. 24, n. 3, p. 443-450, 2006.

UNGER, P.W. Straw mulch effects on soil temperatures and sorghum germination and growth. Agron. J., 70:858-864, 1978. 